LIONEL W. MCKENZIE AND THE PROOF OF THE EXISTENCE OF A COMPETITIVE EQUILIBRIUM

\author{
E. ROY WEINTRAUB \\ CHOPE Working Paper No. 2011-03
}

January 2011

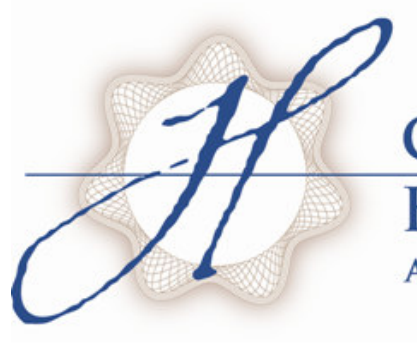

CENTER FOR THE

HISTORY OF POLITICAL ECONOMY AT DUKE UNIVERSITY 


\section{Lionel W. McKenzie and the Proof of the Existence of a Competitive Equilibrium}

By E. Roy Weintraub

Department of Economics

Duke University

Box 90097

Durham, NC 27708-0097

Email: erw@duke.edu 
Abstract of

\title{
Lionel W. McKenzie and the Proof of the Existence of a Competitive Equilibrium
}

\author{
By E. Roy Weintraub \\ Department of Economics \\ Duke University
}

The theorem proving the existence of general equilibrium in a competitive economy, which necessarily involved specifying the conditions under which such an equilibrium would exist, is an extraordinary achievement of twentieth-century economics. The discovery is commonly attributed to the paper by Kenneth Arrow and Gerard Debreu, "Existence of an Equilibrium for a Competitive Economy," which was published in the July 1954 issue of Econometrica. However it is less well-known, even within the economics profession, that Lionel McKenzie published a paper in the previous issue of Econometrica, "On Equilibrium in Graham's Model of World Trade and Other Competitive Systems," which discussed many of the same themes. Over the past decade the new availability of archival material, the papers of Lionel McKenzie, Robert Solow, Gerard Debreu, and Leonid Hurwicz, permits a reexamination of the events surrounding the publication of both Econometrica papers in 1954. The discussion raises general issues concerning "simultaneous discovery," "priority," and "credit" in economic research, and opens a window into some academic practices of that time.

JEL Codes: B2, B3

Keywords: Arrow-Debreu, McKenzie, General Equilibrium, Arrow-Debreu Model 


\section{Introduction}

The theorem proving the existence of general equilibrium in a competitive economy, which necessarily involved specifying the conditions under which such an equilibrium would exist, is an extraordinary achievement of twentieth-century economics. The discovery is commonly attributed to the paper by Kenneth Arrow and Gerard Debreu, "Existence of an Equilibrium for a Competitive Economy," which was published in the July 1954 issue of Econometrica. The citations for the Nobel prizes conferred on Arrow in 1972 and on Debreu in 1983 each refer to their work on general equilibrium theory.

However it is less well-known, even within the economics profession, that Lionel McKenzie published a paper in the previous issue of Econometrica, "On Equilibrium in Graham's Model of World Trade and Other Competitive Systems," which discussed many of the same themes. More specifically, both the McKenzie and the Arrow-Debreu papers established the existence of a competitive equilibrium for suitable general equilibrium models, both papers drew on the Wald $(1934,1935)$ tradition, and both papers employed fixed point theorem arguments. Both papers were presented to a public audience at the same Chicago Econometric Society Meeting in 1952. From that meeting, the McKenzie paper's abstract was published while that of the Arrow-Debreu paper was not, and the McKenzie paper was submitted first, by several months, to Econometrica. Thus, McKenzie had priority in publication in 1954 and received credit for simultaneous discovery in prominent sources around that time. But over the years, McKenzie's role in creating the proof of the existence of a general equilibrium seems to have faded from the collective consciousness of the economics profession.

In earlier work, I told the story of how the McKenzie paper and the Arrow-Debreu paper 
came to public attention (Weintraub, 1983). That narrative was largely based on secondary sources and personal recollections of the authors, because few available archival documents bearing upon that period were at that time available. In the 1990s the papers of Kenneth Arrow and Nicholas Georgescu-Roegen (the associate editor of Econometrica responsible for shepherding the Arrow-Debreu paper through the refereeing and publication process) were deposited in the Duke University Economists Papers Project archive. Those materials allowed Weintraub and Gayer (2001) and Weintraub (2002) to reconstruct in part the publication history of the Arrow-Debreu paper. Over the past decade the new availability of archival material, the papers of Lionel McKenzie, Robert Solow, Gerard Debreu, and Leonid Hurwicz, permits a reexamination of the events surrounding the publication of both Econometrica papers in 1954. The discussion raises general issues concerning "simultaneous discovery," "priority," and "credit" in economic research, and opens a window into some academic practices of that time. 


\section{Setting the Scene}

Lionel McKenzie's only autobiographical piece was delivered orally at Keio University in June 1998 on the occasion of his receiving an honorary degree. The written version appeared in Keio Economic Studies in 1999. In one part of that speech he described the genesis of his 1954 paper, and that short discussion reiterated what he had written to me in the early 1980s as I was writing my 1983 paper. McKenzie began by recalling his time at the Cowles Commission (he was a special graduate student at Chicago) starting in the fall of 1950, and continued with his return to his position at Duke University in fall 1951. McKenzie (1999, pp. 4-5) wrote:

... a piece of research I completed at Chicago was done in Koopmans's class on activity analysis and was based on Graham's model of international trade that I remembered from [my days pre-WWII when I was a doctoral student at] Princeton. It was a multi sector analysis of comparative advantage which showed that bilateral comparison of comparative advantage was not sufficient to discover an efficient allocation of world production. This led to my article in the Review of Economic Studies (1954) entitled "Specialization and Efficiency in World Production”. Koopmans was pleased with this paper and suggested that I stay longer in Chicago, but I felt I should return to Duke ...

On my return to Duke I did not immediately do as Koopmans had suggested to me and consider the factor price equalization theorem of Samuelson in the context of an activities model. The remarks Morgenstern 
made on the existence problem at Princeton and those made by Koopmans at Chicago had interested me in that question. I knew that Graham had given his model of trade to von Neumann to ask for a way of solving for the equilibrium and von Neumann had replied that no analytic solution was possible. I found the Wald and von Neumann papers from the Karl Menger Seminar in the Duke Math Library ${ }^{1}$ and read them with my rather weak German. At this time, I wrote my paper "On Equilibrium and Graham's Model of World Trade and Other Competitive Systems”, published in Econometrica in 1954, but delivered to the Chicago meetings of the Econometric Society in December 1952. This was the same meeting to which the Arrow-Debreu paper on existence was reported. Debreu was present at my presentation and made an intervention to suggest that my paper was implied by theirs, which had been delivered earlier in the meeting. Though I had not heard it, I responded that my paper no doubt implied theirs. Literally both statements were false. Their paper used consumer utility functions and Debreu's theorem on the existence of a social equilibrium, which depended on the fixed point theorem of Eilenberg and Montgomery, while I used demand functions and the more elementary Kakutani fixed point theorem. I had learned

\footnotetext{
${ }^{1}$ When I did my 1983 paper, I too went to the Duke Math Library to find the Menger Ergebnisse papers of Wald and von Neumann. At that time in the 1980s the math library still was changing over to computerized record-keeping, so when I was given the volume, it had a card in the back with previous borrower's names, the only other borrower having been McKenzie!
} 
about the Kakutani theorem from a working paper by Morton Slater, the resident mathematician at the Cowles Commission.

Several points are worth emphasizing. First, both McKenzie and Debreu were unaware of one another's work at the time of the Chicago meeting in December 1952. Second, at that time both McKenzie and Debreu were concerned about the issue of priority. And third, the papers were not identical in their mathematical approach.

\section{Priority Through Seminar Presentations?}

At least since the controversies erupted over James D. Watson's 1968 memoir The Double Helix, it has been generally recognized that priority in discovery is normally rewarded by substantial academic credit, and so priority fights have been common in the sciences. In economics, the relevant date is typically the date of actual journal publication, but given the uncertainties and delays in journal publication (which, as will be discussed in a moment, were manifest in this case), priority claims may also look back at when the discovery was presented in open seminars.

Econometrica published a record of the Chicago 1952 Econometric Society meetings in its July 1953 issue (vol. 21, no.3, pp. 463-490). The "Report of the Chicago Meeting, December 27-29, 1952" noted that on Saturday afternoon, December 27, in a session on the "Theory of Games" chaired by Harold Hotelling, the "Abstract of paper by Arrow and Debreu and of discussion by Savage [is] not available" (p. 473). Thus, the Arrow-Debreu paper had neither been published nor abstracted in the open literature by July 1953 (even though in April 1952 
Debreu had asked Arrow to present their joint paper, which had not yet been written (!), at a conference in East Lansing in September 1952). That same "Report" noted a Selected Papers session of Monday afternoon, December 29, 1952, ${ }^{2}$ chaired by Martin Bronfenbrenner ${ }^{3}$, and provided a four-paragraph abstract of McKenzie's paper titled "The Existence and Uniqueness of Equilibrium in Graham's Model of International Trade.” The last paragraph of that abstract read (p. 484): "From the generality of the proof it is clear that the special nature of Graham's model is irrelevant. The proof actually constitutes a substantial generalization of the results achieved by A. Wald for Cassel's [general equilibrium] model. Also, the proof does not have the rather intricate nature of that used by Wald. The basic source of the added generality and simplicity is the exploitation of the convexity of the set of outputs and the use of a fixed point theorem."

McKenzie saw his claim of priority for his work on the existence of competitive equilibrium to be the equal of Arrow and Debreu, in the sense that they each presented their work on the existence of equilibrium problem at the December 1952 Econometric Society Meeting in Chicago. McKenzie perceived his claim to be weaker in that he appeared to be modeling a specific world trade model, not a general competitive system. However, he had explicitly noted in the published abstract of that paper, and in the paper itself, that the restriction to Graham's trade model was irrelevant to the larger issue of existence of a competitive equilibrium. His use of the Kakutani fixed point theorem, which immensely simplified the structure of the existence proof, arguably made a stronger connection to the underlying economic

\footnotetext{
${ }^{2}$ This is actually two days after the Arrow-Debreu paper presentation by Debreu, not the next day as McKenzie had remembered.

${ }^{3}$ Bronfenbrenner had invited the Japanese mathematical economist Takama Yasui to those Chicago meetings, and he attended both sessions (as discussed further below).
} 
theory than the approach used in the Arrow-Debreu paper which was built on the Nash theorem, based on the Eilenberg-Montgomery fixed point theorem.

However, there were actually four existence papers, not just two published in Econometrica in 1954. The first was a paper done by Arrow at Stanford in late 1951, and circulated at Cowles in Chicago as a technical report done under contract with the Office of Naval Research (I will call it the ONR paper). That paper, titled "On the Existence of Solutions of the Equations of General Equilibrium under Conditions of Perfect Competition", used the Kakutani Theorem to (attempt to) establish a competitive equilibrium. ${ }^{4}$ Second was a paper in draft by Debreu (at Cowles) using the Eilenberg-Montgomery (1946) theorem, and a generalization of it by Begle (1950), to prove existence of equilibrium — but not in a competitive model. That paper, published as Debreu (1952), was written in late 1951 and revised to appear in the Proceedings of the National Academy of Science: I will call it the PNAS paper. ${ }^{5}$ The PNAS paper was submitted for Debreu by NAS member John von Neumann in August 1952. In it Debreu stated that the theorem in the paper "has been used by Arrow and Debreu to prove the existence of an equilibrium for a classical competitive equilibrium system...", and in footnote 2 noted that the Arrow-Debreu paper was in press at Econometrica and scheduled to appear in

\footnotetext{
${ }^{4}$ The paper itself appears to have been lost, although we can reconstruct some parts of it from the extended discussion of it in letters between Debreu and Arrow located by Düppe (2010) in the Debreu papers.

5 As discovered by Düppe (2010), the PNAS paper is a synthesis of Debreu's (1951b). "Saddle point existence theorems," CCDP Mathematics 412, January 4, and his (1952a). "An Economic Equilibrium Existence Theorem," CCDP Economics 2032. The former was written before reading Arrow, the latter after.
} 
1953. That statement was misleading: in August 1952 the Arrow-Debreu paper had not yet been written! The Arrow-Debreu paper was only submitted in the summer of 1953, and would not appear until $1954 .^{6}$

Arrow, seeking distribution and comments on the ONR paper, sent it to Koopmans, the Research Director of Cowles, who asked Debreu to read it in January 1952. Debreu wrote to Arrow in Rome in February 1952 (Arrow was travelling in Europe that semester on a Social Science Research Council Fellowship) with comments. As the two of them worked out errors and lacunae in the ONR and PNAS papers via letter, they agreed by March 1952 to do a joint paper. In the joint paper, a major issue to be settled was how to combine the economic model of Arrow in the ONR piece with the mathematical artillery of Debreu's PNAS paper. Their correspondence resulted in the Arrow-Debreu (1954) paper. $^{7}$

\footnotetext{
${ }^{6}$ The most likely explanation is that the PNAS was lagging in its publication schedule, and the 1952 volume appeared in late 1953. In that case Debreu, copy-editing that paper in 1953, inserted the comments about the emergent Arrow-Debreu paper.

${ }^{7}$ This discussion of the Arrow-Debreu collaboration draws from the exceptional history recently reconstructed in two papers by Till Düppe $(2010,2012)$ which employed the newly availably Gerard Debreu Papers at the Bancroft Library at UC-Berkeley. A version of the first paper was presented in a session at the History of Economics Society Meeting in Syracuse NY in June 2010. A version of the second, from which parts of my own paper are drawn, was presented in London at the Annual UK History of Economic Thought Conference, Kingston University London, September 16-17, 2010) and in Paris (The Foundations, Definitions and Usages of Perfect Competition, International Workshop, co-organized by EconomiX and by les Cahiers d'Economie Politique. Paris, January 13-14, 2011.
} 
McKenzie's paper was begun in very late 1951, and was submitted for the Chicago meetings in Fall 1952. He submitted that December 1952 paper to Econometrica in the first few months of 1953. Part of McKenzie's strategy in seeking an equal claim to priority with respect to Arrow-Debreu was to present an expanded version of his paper, making clear that its generality extended beyond the Graham model. He planned to present it at the Summer Meetings of the Econometric Society in Kingston, Ontario, in September 1953. He thought that the published abstract of the paper would then appear before either of the published papers by him or ArrowDebreu. Robert Solow appears to have been the chair of the program committee for the Kingston meetings, and on April 9, McKenzie wrote to him:

I have recently extended Wald's theorem to general linear models assuming only continuous demand functions and Kakutani's theorem. I think this has been most significant to extensions since a long period of competitive equilibrium virtually requires linearity. My proof can be neatly illustrated with a two dimensional diagram. It is the general form of the paper I presented on Graham's model last December.

Concerning that developing paper, McKenzie sent a message to Robert Strotz, the Managing Editor of Econometrica, on April 25, 1953, and mentioned in passing: "I've definitely carried Wald's theorem to its ultimate conclusion by including the case of external economies. I hope to have a MS soon." This was to be the paper McKenzie presented at Kingston that September. On May 1, 1953, Solow responded concerning the Kingston meeting: 
I confess to being slightly awe-struck at your rate of production of new theorems, but I am the slow and slothful type myself. In any case, the extensions of Wald's theorem that you describe strikes me as being intensely interesting. By all means get them on record at Kingston. In fact, if you get them written up before then, I would very much appreciate giving a look at your results. I would have thought that the existence of external economies would enormously complicate the problem. Perhaps it is the assumption of inelastic supply of capital goods that saved the day. If I understand you correctly, the very possibility of saturation with capital might serve the same purpose. This sounds like a great step forward. You apparently know of Debreu's results along this line. Ken Arrow has also been working on this problem, and the two of them are publishing a joint paper to appear in Econometrica some time soon. Perhaps the best thing for you to do is simultaneously to plan on reporting your results at Kingston, and on submitting a paper to Econometrica.

From this note, Solow appears to have been unaware that McKenzie had given a paper at the previous December meeting that was related to the Arrow-Debreu paper, and further he was unaware that McKenzie had already submitted that paper to Econometrica early in 1953 (probably in March), months before the Arrow-Debreu submission (Weintraub and Gayer, 2001; Weintraub, 2002, 192 et seq.).

McKenzie presented his new paper in Kingston, Ontario, on September 3, 1953. There is no evidence that Arrow or Debreu attended those meetings in Kingston, the program for which 
was published in the October 1954 issue of Econometrica (pp. 511-512). However, McKenzie's hopes of a second abstract in Econometrica were dashed as he received a letter from Strotz on September 29, 1953 which apologized: “As for your abstract, you will grieved to know that present plans, which are, however, still tentative, are to cease publishing abstracts of papers given at meetings. A main reason for this is to economize on space in the journal. I believe this will mean that the abstracts of papers given at the Kingston meetings will not appear, although this is not yet quite definite. It was good to see you again [at Kingston] and I look forward to the next time." The note from Strotz meant that there would be no recognition of McKenzie's now more general theorem in print before both of the original papers had appeared.

\section{A Sluggish Editorial Process}

McKenzie submitted the existence paper to Econometrica in March 1953. Managing Editor Strotz assigned Robert Solow, one of the journal's Associate Editors, to handle the McKenzie manuscript. However, Solow never wrote directly to McKenzie: all editorial communication between McKenzie and Econometrica went through Strotz.

Through the rest of 1953, a series of letters from Strotz to McKenzie lamented the sluggishness of the referee process. For example, Strotz wrote to McKenzie on June 9, 1953, "I am writing to tell you that I have prodded the referees, who seem to be particularly pokey. I do not want to give you any encouragement regarding the speed with which this processing can be brought to a conclusion, but I do hope that reports might start coming in quite soon." Soon 
thereafter, Strotz wrote on June 23, 1953:

Dear Mac: I thought I better write to you to explain that despite our recent promptings of the referees of your manuscript, we have to this date heard nothing from them. This is very bad luck. Your paper is in the hands of two different people and neither have [sic] so far sent me any word about it. Knowing how busy people are with the conclusion of the academic year, it is not surprising that nothing happened during the month of May or the first part of June; but one would hope that they could busy themselves with it during the past two or three weeks. I wonder what to do in this case: whether to write to them and recall the manuscript or simply to prompt them again and keep hoping to hear. If the paper is to be recalled, this means that its processing must be started once again and the past several months of waiting will be a complete loss. On the other hand, one hates to throw good time after bad. Since you are the one who has the personal interest in the matter, I thought I would write to you to ask your advice. My own recommendation is, I believe, that another prompting letter and a further wait would be in order for I should certainly hope that this would spur them to some immediate action. I am planning to get to Kingston this year; I'll look forward to seeing you there. It occurs to me that I ought to reassure you in connection with your manuscript that I shall not publish any similar papers submitted after yours was submitted before 
publishing yours, provided, of course, that your paper is found to be acceptable .

Strotz then wrote McKenzie on August 6, 1953: "I have given up. Letters have gone to both referees requesting the return of your manuscript to this office right away. I hope to God I can have better luck with the next people. I don't know whether this is a matter of concern to you, but let me assure you that it is my intention not to publish the paper by Arrow and Debreu (which has also been submitted) before the publication of your paper (if both are found acceptable). I think this would only be fair to you." It is clear that Strotz was aware of the priority issue.

There is one last entry in this sequence. Strotz wrote to McKenzie on August 17, 1953, that "as might be expected, a recent demand that your manuscript be returned by the two tardy referees has brought a brief comment from one of them, with the promise of more detailed comments within a few days. I have already arranged for someone else to take over the refereeing of your paper from the other laggard and hope that we can make some speed from here on in."

On December 14, 1953, eight months after his original submission, McKenzie received a letter from Strotz which read:

At last I can report to you on your manuscript entitled "On Equilibrium in Graham's Model of World Trade and Other Competitive Systems". The paper is favorably refereed and I am today writing to Professor Frisch [Editor of Econometrica] to recommend it for publication. I feel quite 
confident that he will concur in this recommendation. At the same time, it appears that a fairish amount of revision is desirable, although it is thought that the desired revision would not take a great deal of time to effect. What has happened is that your paper has actually been read thoroughly by only two persons. Let me call them referees number one and number two. Number two, in addition to making his own comments, read the comment of number one and commented on the comments. I'm enclosing copies of all this material, properly labeled.... My goal is to get your paper into the April issue if at all possible. This means that I really ought to get your revision along about the middle of January if this can be done.

On January 18, 1954, approximately nine months after McKenzie's original submission, Strotz sent him some referee comments. Strotz then wrote to McKenzie on January 26, 1954, letting him know that he had marked up the paper for the printer, and mentioned: "Frisch has written me about the exposition of the mathematical material in your paper and I am enclosing an excerpt from his letter dealing with this subject with the thought that you, better than I, might take a stab at changing a few things so as to satisfy him." The excerpt that Strotz enclosed from Frisch's letter began with the sentence “The Lionel McKenzie MS on Equilibrium in Graham's Model on World Trade and Other Competitive Systems is accepted."

Strotz kept his promise about order of publication. The McKenzie paper appeared in the April 1954 (vol.22, no. 2) issue of Econometrica, while the Arrow-Debreu paper appeared in the July 1954 (vol. 22, no. 3) issue. 


\section{The Editorial Process Unmasked}

As the papers of various economists and journals have become available, we can now see more clearly what was happening in the editorial process for McKenzie's paper. Its original referees were Leo Hurwicz and John Nash (Weintraub and Gayer, 2001). They did not do their jobs. Eventually Strotz as Managing Editor, through the agency of his Associate Editor Robert Solow, asked for another referee even as Hurwicz, one of the original referees, sent in a short positive report. Hurwicz's report was sent to Debreu by Solow on October 5, 1953 together with a request that Debreu himself referee the McKenzie paper. This series of events set the stage for a remarkable letter of September 13, 1966, from Debreu to Solow:

Dear Bob: I may have been responsible in 1953 for a misconception which I find to be spreading. I believe I should endeavor to dispel it. On October 5, of that year, you asked me to referee for Econometrica the article by Lionel McKenzie that eventually appeared in the April 1954 issue. Your request put me in an awkward situation, for on June 9, 1953, Kenneth Arrow and I had sent to Robert Strotz for publication in Econometrica the joint paper that was published in the July 1954 issue. The results of our joint paper were more general than those of Lionel in several ways and the main mathematical result on which our work was based was also a fixed point theorem for set-valued functions. The difference between the two papers in this respect was that Lionel used Kakutani's theorem whereas we used the theorem I had published in Proceedings of the National 
Academy of Sciences, October 1952 which rests on the generalization of Kakutani's theorem due to Eilenberg and Montgomery. We hoped thereby to be preparing the way for a theorem on the existence of a competitive equilibrium which would not depend on convexity assumptions. My Proc. Nat. Acad. Sc. article was sent to John von Neumann on May 29, 1952. The idea of using a fixed point theorem for set-valued functions to obtain an existence proof for the equilibrium of a competitive economy had occurred to Ken and me several months before. In my referee's report of December 17, 1953, I leaned away from the temptation to tell you all this and tried to evaluate Lionel's paper on its merits denying myself use of the information that I have just imparted to you. As a result, my report was undoubtedly confusing. I began to wonder whether I should write to you about this matter some seven or eight years ago when I read footnote 1, p. 374, of Dorfman-Samuelson-Solow [Linear Programming and Economic Analysis. New York: McGraw Hill, 1958]. I hope I am not too hasty in writing today.

The footnote to which Debreu referred began: "The use of the Kakutani theorem to prove the existence of an equilibrium is McKenzie's idea. See his study of Graham's internationaltrade model ..." Debreu objected to this remark, stating that the idea for the proof - the fixed point theorem - had occurred separately to him and to Arrow in late 1951, a statement that is supported by Düppe's (2010) chronology. But Debreu's note also offered the admission as that at a time when he was concerned about priority via-a-vis McKenzie, he was asked to act as a 
referee for McKenzie's paper, and he apparently did not mention this to the journal editor. In fairness, Debreu may have been unaware that the McKenzie paper had been submitted several months before his own: his letter expressed the false belief that the McKenzie paper was a new submission of the paper read in at the Chicago meetings the previous December.

\section{Some Reflections on Past Journal Practices}

This narrative calls attention to the professional journal practices revealed by the publication experiences of the Arrow-Debreu and McKenzie papers at Econometrica. Econometrica in the early 1950 s was a coterie journal, created along with the Econometric Society in the early 1930s. Compared to the generalist journals like American Economic Review, the Journal of Political Economy, and the Quarterly Journal of Economics, in the early 1950s Econometrica had relatively few readers. Although the economics profession was changing in the early 1950s, economists with only pre-World War II training in economics would have struggled to read the sophisticated mathematical and statistical work published in

\section{Econometrica.}

In this situation, the more sophisticated readers of the journal formed a small group meeting at conferences, circulating papers to one another, and being generally aware of work being done by like-minded economists around the world (Crane, 1972). At that time, Econometrica would have received a relatively small number of submissions and had only a small number of individuals who might have been called upon to edit and referee papers. This situation helps to provide a context for the practices that characterized the journal's treatment of the Arrow-Debreu and McKenzie papers. As Associate Editor Georgescu-Roegen wrote 
(October 8, 1953) to Strotz concerning the submission of the Arrow-Debreu paper: "[T]he mathematics and the economics are so much inter-woven in the argument that I found it difficult to think of many referees who would be at the same time economists and mathematicians so that the critical reading of the paper would not impose upon them a tremendous task." He then went on to note that the referee comments from Baumol and Phipps were unhelpful, and that he himself was thus providing comments to Arrow and Debreu saying: "I have the highest opinion of the authors and I trust Debreu's mathematics, yet I recommend that somebody check the mathematics. This could be done while the authors revise the present version, thus saving considerable time.”

This comment from Georgescu-Roegen confirms that the Arrow-Debreu paper was not comprehensively refereed in a modern sense, and we know that the McKenzie paper was only lightly read by Hurwicz before it was "refereed" by Debreu, who in the modern period would not have been allowed even to read the paper without McKenzie's approval. ${ }^{8}$ That Debreu did not believe, at the time, that he should have recused himself from that process, and that no editor expressed discomfort with the practices apparently in place, creates a curious picture of the insular nature of the intellectual community about to come into prominence in economics.

\footnotetext{
${ }^{8}$ In a comment to me on the current paper, Robert Solow $(2010$, p. 1) mused: "To whom could I have sent the [McKenzie] paper? I could have asked Paul [Samuelson], but he was always so busy that one hesitated to burden him. The community interested in and competent in those questions was trivially small. Leo had been used; Nash was a bad choice. Hicks was impossible, as was Allais...It really was a tiny coterie."
} 


\section{Simultaneous Discovery and Priority}

Ideas of priority and simultaneous discovery appear throughout this narrative. The McKenzie, Arrow (ONR), and Debreu (PNAS) proofs all seem to have been conceived independently at about the same time in late 1951. And prompted by my question to him about his connection with Debreu in Chicago in 1950-51, McKenzie wrote to me (September 8, 2009):

Actually I did visit the Cowles Commission in Chicago when Debreu was there and working on existence, but he kept this fact secret from me. I asked him what he was working on and he refused to say. The first thing I knew about his work was when we both presented papers on existence to the Chicago meeting of the Econometric Society in 1952. I did not hear his paper but he heard mine and alleged there that my result was implied by his. I entered the possibility that his was also implied by mine. Both allegations were wrong, since he assumed that demand functions were derived from continuous preferences and I assumed that they were continuous and at sufficiently low prices would exceed the production limits. I cited their paper in mine but they did not pay me the same courtesy. Arrow told me that this was because Debreu did not tell him about my paper. Also they assumed free disposal without acknowledgement. In my final section I described a general linear model similar to my later work. 
Recall that McKenzie had returned to Duke in Fall 1951 to work on his existence paper, using Kakutani's theorem as developed in the notes written by Morton Slater that he had obtained in his year at Cowles in 1950-51. It is thus impossible to say from any published record or unpublished letter or note whether McKenzie or Arrow or Debreu first had had the idea, or had employed the technique, of using a fixed point theorem to establish equilibrium. The case for "simultaneous discovery" is nearly unassailable.

Nor can a priority claim be established from the first presentation of the idea to a third party. Arrow, at Stanford, sent his ONR paper, which apparently had several gaps and errors in its proofs, to Koopmans at Cowles in January 1952 at the latest (since Arrow had left for Europe by December 1951), and completed his report before his departure, probably in November 1951. Koopmans gave it to Debreu. Debreu was talking regularly with Mac Lane others at Chicago, but his own PNAS paper was incomplete, and in early 1952 gaps and errors remained in his own proofs, as confirmed by his letter to Arrow in February 1952 (Düppe, 2010). We have no record of McKenzie's showing his own paper to anyone prior to submitting it for presentation at the 1952 Chicago meeting. Consequently no case for priority can be made on the basis of a public examination of the new idea by a third party.

The first independent public presentation of the existence proofs at the December 1952 Chicago meeting. Debreu twice noted in his letters to me that his paper with Arrow had been presented at a session of those meetings before McKenzie's session. Yet certainly the program could have had those sessions reversed. Thus, with respect to which paper was first read in public (and of course they were not read in their entirety in the session), they were in practical terms simultaneous. ${ }^{9}$

9 We do know that the Arrow-Debreu paper was submitted with a cover page stating its origin as 
With respect to priority in publication, the referee process for the two 1954 papers was messy. The Arrow-Debreu paper, submitted at least two months after McKenzie's submission, was refereed by William Baumol and Cecil Glenn Phipps (of the University of Florida mathematics department), each of whom did his work quickly, with no prodding needed. ${ }^{10}$ McKenzie's referees, selected before any were chosen for the Arrow-Debreu paper, were Leonid Hurwicz and John Nash. Whether Hurwicz had then the reputation that he later developed, of not reading his mail or replying in a timely fashion, is not clear. Nor is it clear that those not immediately connected with John Nash knew of his illness. In any event, McKenzie had bad luck to have drawn these initial referees. .

Strotz's decision to publish McKenzie's paper first, reflecting its submission before the Arrow-Debreu paper, meant that McKenzie could claim publication priority. But the contingencies of the editorial process at Econometrica should make that claim a weak reed to support McKenzie's priority. This narrative compels only the claim that the two papers were essentially simultaneous.

an Office of Naval Research Technical Report (Weintraub and Gayer, 2001, p. 428; Weintraub 2002, p. 192). We have no evidence, nor was any ever proffered, from Arrow, Debreu, or McKenzie that there were comments made on the papers prior to the Chicago meeting that might be traced through third party files still extant. Indeed, Düppe (2010) has discovered that Arrow and Debreu themselves were not fully in agreement on the structure of their joint paper.

${ }^{10}$ Phipps famously recommended that the paper be rejected, and was irate that his advice was ignored (Weintraub and Gayer, 2001). 


\section{How Academics Give Credit}

The proof of the existence of competitive equilibrium in a market economy by McKenzie and by Arrow and Debreu in the early 1950s seems to present a case of essentially simultaneous discovery, presentation, and publication. However, by the late 1950s, textbooks began mentioning the Arrow-Debreu paper as having established the existence of a general equilibrium for a competitive economy (Weintraub and Gayer, 2001), while McKenzie's paper seemed to have dropped from sight. A current search using Google Scholar yields around 2300 cites of the Arrow-Debreu paper, and 197 cites of the McKenzie paper. Given the essentially simultaneous discovery, what explains the asymmetric credit? There are two possible explanations: one rooted in the details of the proofs themselves, and one rooted in the sociology of academia.

For the modern economist, a common answer is that the Arrow-Debreu version of the proof was "better," which in this context can mean more general, more elegant, or more influential. But such judgments can be unclear and variable over time.

In the context of the 1950s, for example, a case can be argued that the McKenzie proof was "better." On October 8, 1953 Georgescu-Roegen, in transmitting to Strotz the two referee

reports on Arrow-Debreu by Baumol and Phipps, made a plea for simplifying that paper: "Would it not be possible either to make the proof more elementary and simpler or to present it as elaborated consequences of other well-known theorems? I heard at Kingston the paper given by McKenzie and was impressed by the very small place occupied by the technical mathematical proof in the argument." Thus Georgescu-Roegen, who had heard the McKenzie paper in Kingston, was asking Strotz to ask Arrow and Debreu to simplify their proof along the lines of McKenzie's, using an exposition of the Kakutani theorem! 
By the 1960s, it was fairly clear to mathematical economists that the Kakutani theorem was the preferred method of demonstrating the existence of equilibrium for a competitive general equilibrium model. This view likely resulted from the 1959 Theory of Value by Debreu, which introduced the Kakutani theorem in its introductory chapter and employed it in the existence proof of its Chapter 5. Debreu's "Preface" made no mention of McKenzie's work in its narrative of the development of the theory up to 1959, a narrative that credited Wald, von Neumann and Morgenstern, Koopmans, and of course Arrow. Yet as noted earlier, both early referees like Georgescu-Roegen and contemporary treatments like the Dorfman-Samuelson-Solow volume of 1958 attributed the use of Kakutani in the proof to McKenzie.

Modern economists are more prone to argue that the Arrow-Debreu proof was "better." For example, in their magisterial review of Arrow's Collected Works, Duffie and Sonnenschein (1989, p. 571) argue:

The Walrasian theory of value has been criticized for failing to take into account the fact that an agent may judge quality by price, or be inconsistent in his choices (as when preferences are not transitive), or have preferences that depend on the choices of other agents. The original Arrow-Debreu proof, unlike the proofs that work via the construction of an excess-demand function (such as McKenzie $1954 \ldots$...), is relatively easily modified to take into account all of these ingredients.

In this telling, the Arrow-Debreu proof is "better" because it is more congruent with the interests of modern theorists. My own interpretation would be that the mathematical details of the theorem and its proof did not compel the disproportionate award of credit to Arrow and Debreu, 
but rather that the community of economists determined that award of credit and interpreted the theorem and proof as supporting that credit over time.

The competing explanation for McKenzie receiving less credit than Arrow and Debreu is rooted in what Robert Merton (1973, p. 445, reprinted from 1968) called the "Matthew Effect" in his The Sociology of Science. He noted that there is a tendency to give greater credit to those who are better known, and quoted the Gospel according to St. Matthew: "For unto every one that hath shall be given, he shall have abundance: but from him that hath not shall be taken away even that which he hath.” In 1954 McKenzie, lacking a Ph.D., was teaching at his alma mater Duke University, a segregated Southern university with a weak graduate program and no presence in economic theory. He had been floundering at Duke in the late 1940s; as he wrote to his friend Ian Little in 1950: "The purpose of [my] trip to Chicago is to get some fresh air intellectually speaking, learn a bit of statistics, and perhaps make a new start. I don't know." When McKenzie received his doctorate in 1957 from Princeton, he moved from Duke to the University of Rochester, which had no doctoral program in economics at that time.

In contrast, Arrow in the mid-1950s, was a Ph.D. student of Harold Hotelling, had been at Cowles and RAND, and had taught at Stanford and was headed to Harvard. Debreu had been a student of mathematicians like Henri Cartan at the Ecole Normale Supérieure, and, in Chicago, had been in contact with mathematicians like Saunders MacLane, John Milnor, I. N. Herstein, and Andre Weil. Mentored by Maurice Allais, Debreu had come to the United States to the Cowles Foundation, moved with that group to Yale, and eventually settled at UC-Berkeley. Over the post-1954 years, both Arrow and Debreu were located in highly prestigious academic institutions, while McKenzie remained by comparison an academic outsider.

A full account of how the asymmetric credit for the proof of the existence of competitive 
equilibrium evolves would need to come to grips with the mathematical details of the proofs, as they were built up in subsequent work, and with these sociological factors. But the bottom line is clear: McKenzie felt that he had been marginalized in the award of credit, ${ }^{11}$ while Debreu believed that McKenzie's claim was based on a less general model and a less general mathematical technique. Over time, these tensions abated somewhat. In his 1983 Nobel Prize speech, Debreu acknowledged McKenzie's work: "In addition to the work of Arrow and me, begun independently and completed jointly, Lionel McKenzie at Duke University proved the existence of an 'Equilibrium in Graham's Model of World Trade and Other Competitive Systems' [1954] also using Kakutani’s theorem.” In his Presidential address to the Econometric Society, given in Ottowa and Vienna in 1977, a revision of which was published several years later, McKenzie (1981, p. 819) says he wished to "discuss the present status of a classical theory on existence of competitive equilibrium that was proved in various guises in the 1950s by Arrow and Debreu, Debreu, Gale, Kuhn, McKenzie, and Nikaido. The earliest papers were those of Arrow and Debreu, and McKenzie, both of which were presented to the Econometric Society at its Chicago meeting in December, 1952. They were written independently. The paper of Nikaido was also written independently of the other papers but delayed in publication."12

${ }^{11}$ McKenzie wrote several personal letters (for example, to Morris B. Abram) recalling his bad luck and referring to the Nobel Prize, which suggests that the bad luck he was himself recalling had to do with the difficulty he had publishing his 1954 paper quickly enough to establish a more clear priority for his own work on the existence of equilibrium.

${ }^{12}$ The issue of credit for Hukukane Nikaido's contribution raises many complex issues.

Nikaido's mentor, Takama Yasui (Weintraub, 1987) had been invited by Martin Bronfenbrenner 
Academics should practice generosity in acknowledging parallel independent contributions: after all, the awarding of professional and intellectual credit need not be a zerosum game - and certainly not when it occurs more than a half-century after the discovery. It detracts not one iota from the remarkable accomplishment of Kenneth Arrow and Gerard Debreu to point out that Lionel McKenzie also deserves great credit in the economics profession for the proof of the existence of general equilibrium.

to present a paper at the 1952 Chicago Meetings, and he attended both the McKenzie and Debreu sessions. Nikaido had independently developed a proof of existence of a general competitive equilibrium using the Kakutani theorem at that time, but it was not until he read McKenzie's paper in 1954 that he believed his own paper might find a place in an English-language journal. His difficulty getting his paper published led to his belief that he might have been ill-treated. The story of this is well told by Aiko Ikeo (2009), based on interviews with both Yasui and Nikaido. 


\section{Acknowledgements}

The papers of Kenneth J. Arrow, William J. Baumol, Nicholas Georgescu-Roegen, Leonid Hurwicz, Lionel W. McKenzie, and Robert M. Solow are all housed in the Economists Papers Project of the Rare Book, Manuscript, and Special Collections Library at Duke University. I appreciated the extensive assistance given to me by the library's staff, particularly by Elizabeth Dunn, as I used those materials to develop my arguments.

I gratefully acknowledge very helpful comments on earlier drafts of this paper from Kenneth Arrow and Robert Solow. With the usual caveats I also benefited from comments from a number of individuals at workshops where I presented an early version of this paper: I thank Philippe Fontaine, Yann Giraud, Roger Backhouse, Mary Morgan, Pedro Duarte, José Raymundo Chiappin, Marcel Boumans, Neil DeMarchi, Craufurd Goodwin, Tom Nechyba, and Beatrice Cherrier. I am particularly grateful to Till Düppe who generously made his current working papers on Gerard Debreu available to me, and in extensive correspondence corrected a number of my errors. The Editor David Autor, Co-Editor Charles Jones, and particularly Managing Editor Timothy Taylor were immensely helpful as I reshaped the manuscript for this journal. I am also pleased that Lionel McKenzie was able to read, even though he believed it would have been inappropriate for him to comment upon, an early draft of this paper several months before he passed away on October 12, 2010 at the age of 91. 


\section{References}

Arrow, K. J. and G. Debreu (1954). "Existence of an Equilibrium for a Competitive Economy."

Econometrica 20: 265-290.

Begle, E. G. (1950). "A Fixed Point Theorem." Annals of Mathematics 51(3): 544-550.

Blank, R. M. (1991). "The Effects of Double-Blind versus Single-Blind Reviewing:

Experimental Evidence from The American Economic Review."

The American Economic Review 81(5): 1041-1067.

Chubin, D. E. and E. J. Hackett (1991). Peerless Science: Peer Review and U.S. Science Policy. Albany NY, State University of New York Press.

Crane, D. (1972). Invisible Colleges: Diffusion of Knowledge in Scientific Communities. Chicago, University of Chicago Press.

Debreu, G. (1951a). Saddle point existence theorems. Cowles Commission Discussion Paper. Chicago.

Debreu, G. (1952b). An Economic Equilibrium Existence Theorem. Cowles Commission Discussion Paper. Chicago. 
Debreu, G. (1952). "A Social Equilibrium Existence Theorem." Proceedings of the National Academy of Science 38: 886-893.

Debreu, G. (1959). The Theory of Value. New York, John Wiley.

Debreu, G. (1984). "Economic Theory in the Mathematical Mode." American Economic Review 74(3): 267-278.

Duffie, D. and H. Sonnenschein (1989). "Arrow and General Equilibrium Theory." Journal of Economic Literature XXVII: 565-598.

Düppe, T. (2010). “Arrow and Debreu de-Homogenized”. Working paper, Institute for the History of Economics, University of Hamburg.

Düppe, T. (2012, to appear). "Gerard Debreu's Secrecy: His Life in Order and Silence" History of Political Economy.

Eilenberg, S. and D. Montgomery (1946). "Fixed Point Theorems for Multi-valued Transformations." American Journal of Mathematics 68: 214-222.

Ikeo, A. (2009). How Modern Algebra was used in Economic Science in the 1950s. History of Economics Society Annual Meeting. Denver, Colorado. 
Kakutani, S. (1941). "A Generalization of Brouwer's Fixed Point Theorem." Duke Mathematical Journal 8: 457-459.

McKenzie, L. W. (1951). "Ideal Output and the Interdependence of Firms." Economic Journal(61): 785-803.

McKenzie, L. W. (1953-4). "Specialization and Efficiency in World Production." Review of Economic Studies 21: 165-80.

McKenzie, L. W. (1954). "On Equilibrium in Graham's Model of World Trade and Other Competitive Systems." Econometrica 22: 147-161.

McKenzie, L. W. (1981). "The Classical Theorem on Existence of Competitive Equilibrium." Econometrica 49: 819-841.

McKenzie, L. W. (1999). "A Scholar's Progress." Keio Economic Studies 36(1): 1-12.

Merton, R. K. (1973). The Sociology of Science. Chicago, University of Chicago Press.

Nash, J. (1950). "Equilibrium Points in N-Person Games." Proceedings of the National Academy of Science 36: 48-49.

Solow, R. (2010). "Letter to E. Roy Weintraub". 26 May 2010. 
Wald, A. (1934). Über die eindeutige positive Lösbarkeit neuen Produktionsgleichungen (I).

Ergebnisse eines mathematischen Kolloquiums, 1933-34. K. Menger. Leipzig and Vienna, Franz Deuticke.

Wald, A. (1935). Über die Producktionsgleichungen der ökonomischen Weltlehre (II).

Ergebnisse eines mathematischen Kolloquiums, 1934-35. K. Menger. Leipzig and Vienna, Franz Deuticke.

Watson, J. D. (1968). The Double Helix: A Personal Account of the Discovery of the Structure

of Dna. New York, Atheneum.

Weintraub, E. R. (1983). "The Existence of a Competitive Equilibrium: 1930-1954." Journal of Economic Literature 21(1): 1-39.

Weintraub, E. R. (1987). "Stability Theory Via Liapunov's Method: A Note on The Contribution of Takuma Yasui." History of Political Economy 19(4): 615-620.

Weintraub, E. R. and T. Gayer (2001). "Equilibrium Proofmaking " Journal of History of

Economic Thought 23(4): 421-442.

Weintraub, E. R. (2002). How Economics Became a Mathematical Science. Durham, NC, Duke University Press. 